\title{
Consciousness and the Philosophy of Signs: A New Précis
}

\author{
Marc Champagne \\ Kwantlen Polytechnic University
}

\section{Lecture delivered 17 December 2019 to the Toronto Semiotic Circle. ${ }^{1}$}

\section{Introduction}

will be talking today about the limits of cognitive science. I won't be talking about contingent shortcomings that could perhaps be remedied with, say, more time, resources, or ingenuity. Rather, I will be concerned with limitations that are "baked into" the very enterprise. The main blind spot, I will argue, is consciousness-but not for the reasons typically given.

Cognitive science has experienced significant growth in the last decades, so why should one consider consciousness elusive-or at any rate more problematic than other objects of scientific study? In the philosophy of mind literature, there are many thought-experiments and arguments that aim to establish that (at least some aspects of) consciousness cannot be captured by regular scientific explanation. The most memorable, in my estimate, is Frank Jackson's $(1982,1986)$ knowledge argument.

Jackson argues that, if a neuroscientist named Mary were to be raised in a black-and-white environment from birth and taught everything about vision and colour science, her extensive knowledge would still not enable her to know, in advance of a genuine encounter, what it's like to see red.

${ }^{1}$ Editor's Note: The Toronto Semiotic Circle lecture represented in this slightly edited transcript was co-hosted by the Ryerson University Department of Philosophy and the Meaning Lab (Department of Languages, Literatures \& Cultures). Since the précis consists entirely of new material, it functions both as a companion piece to the preceding book review of the same title and as a fresh take on the book's core argument. 
She can learn much about that colour in her monochrome setting. But, even with access to a completed neuroscience, she will appreciate the experiential quality of red only upon her release.

I'm a big fan of this argument. Jackson's scenario, however, calls on some science-fiction that gives me pause. For one thing, doctoring a blackand-white environment is admittedly just an idealization. For instance, if one worries that Mary might experience red by seeing her blood, one can alter the story so that she wears special colour-negating goggles and so on. Alas, these ad hoc fixes make the starting scenario far-fetched. More problematically, the story requires Mary to be maximally informed, but no single human can be maximally informed about any science-let alone all the sciences needed to exhaustively comprehend color vision.

As a result of these outlandish assumptions, there will always be those (like Dennett 1991: 399-400) who suspect that the knowledge argument's conclusion is dubious. That is a shame, since in principle the qualitative dimension of consciousness should be something that we are all familiar with. I therefore want to avoid speculative detours and instead articulate the basic philosophic worry using only ordinary premises.

Current work in philosophy of mind can sometimes seem arcane, so my goal today will be to answer the question: why bother? I have spent a whole book and several articles trying to make sense of the qualitative dimension of consciousness, but there is no point in trying to sell a solution unless we have first established (independently of any academic literature) that there is a real problem to solve. So, if I can't convey my position in under an hour, I can at least convey the issue that motivates it.

For what it's worth, I have decided not to rehearse any previous material, so everything I will say today is a fresh gloss-one that I am fortunate to make with the benefit of some hindsight. So, if anything I say sounds incomplete, it is probably because it is. For those wishing to fill the gaps, the companion piece to this talk is the book by the same name (Champagne 2018).

\section{The Ordinary Knowledge Argument, Less Comfortable Version}

With that orientation and caveat in mind, let me start with two premises which I trust everyone will accept. First: humans are capable of having orgasms. We can add to this another uncontroversial claim, namely that humans are capable of using language. Putting aside science-fiction, an acknowledgement of these two claims generates a problem. Let me outline how. 
The human experience of orgasms and the human use of language both unfold diachronically, so there had to be a time when both were absent from one's cognitive life. One consequence of this unfolding in time is that most of us learned the word "orgasm" before we actually experienced one. The usual developmental timeline, then, seems to have three distinct segments. First, there was a period when one did not have any orgasm and did not even know the word for that. Next in line was a period when one generally knew the word but still had not undergone the particular experience it picks out. Finally, there came a time when one underwent one's first orgasm, thereby augmenting one's earlier mastery of the relevant bit of language with a first-hand experience.

I am not concerned with how long each segment of this timeline lasted, but only with the possibility that events can unfold in that order: total ignorance, followed by hearsay, and finally first-hand appreciation. Some individual lives no doubt unfold differently. One could, for instance, experience an orgasm before learning the word for that. Nevertheless, given the (arguably standard) sequence of events just outlined, the second segment becomes philosophically interesting.

There was presumably a time in one's life when, despite never having had an orgasm, one knew how to deploy the word in appropriate contexts; using it grammatically in conversations, and so on. In other words, passing the Turing test in front our peers, we faked it until we made it.

Now, suppose that, in a bid to improve one's linguistic performance, one asked a more experienced friend to describe in more detail what it's like to have an orgasm. A person in the know might give the following answer: you become all warm, it tingles, you momentarily forget where you are, your body stiffens, it's like the feeling of release that you get in a hot shower after a hard workout, and so on.

Such replies can vary, but they all essentially try to reason by analogy. One takes a qualitative feel and attempts to convey the quality in question by appealing to similar qualitative feels. You will notice that this communicative strategy is premised on two assumptions. First, it is assumed that the descriptions each pick out experiences that the question-asker has already undergone-otherwise these descriptions will in turn be unknown and thus compound the starting problem by leading to a regress. If one has never felt a tingling sensation, that analogy will not be very informative. Second, it is assumed that experiences sum, such that many conjoined descriptions can shed light on a single qualitative experience. An orgasm is a unitary experience, but we deploy a battery of adjectives to describe it. 
Our everyday talk nevertheless makes it seem that, if one is able to analyze the feeling of an orgasm as the feeling of heat, the feeling of tingling, and the feeling of slight dizziness (say), one can simply add a plus sign between those parts to obtain the sum. This is, however, wildly implausible. I might say, in an ordinary conversation, that wasabi is like tasting hot sauce while sneezing. However, someone who tries to recreate that experience by sipping on Tabasco sauce and blowing her nose will not succeed in producing the taste of wasabi. The same goes for orgasms, which (thankfully?) cannot be produced by jointly doctoring sensations of heat, tingling, and slight dizziness. This fact alone should cast doubt on the ability of language to do the referential work required.

This dubious tally and threat of regress notwithstanding, what matters for my purpose is that a word is explained with still more words. This attempt to explain a word with words may look circular, but the truth is that a large enough circle can achieve wonders. A dictionary, for example, does just that. Yet, what has been said about the translation manual of John Searle's (1980) Chinese room is equally applicable to a dictionary in one's native language, namely that, without an appreciation of the referents, "[t]he trip through the dictionary would amount to a merry-go-round, passing endlessly from one meaningless symbol or symbol-string (the definiens) to another (the definiendum), never coming to a halt on what anything meant" (Harnad 1990: 339). If a network of word-to-word relations is sufficiently large and sufficiently systematic, it can provide knowledge, albeit only knowledge of the sort that Bertrand Russell (1910-1911) called "knowledge by description". What is missing, ostensibly, is "knowledge by acquaintance".

Now that we have introduced this important analytical distinction, imagine that the person wishing to know more about orgasms decided to learn all the knowledge by description that one can possibly acquire about that subject. Since people can write down their first-person reports, such an armchair student of orgasms would have access to texts aiming to be maximally descriptive (like something written by a trained phenomenologist), as well as texts aiming to be maximally evocative (like something composed by a poet or romance novelist). In addition, one could read biology textbooks, watch video footage of people undergoing the experience, and whatever else isn't an orgasm itself. The question is: Could such theoretical learning, pushed to its maximum, ever allow one to know what it's like to have an orgasm?

To gauge the likelihood of this, imagine that one's high school friend returned from a long reading session at the library to boast that he/she 
knew-without ever having one-what it feels like to have an orgasm. How seriously would we take that claim to knowledge? Surely, most of us would scoff at such a boast.

Recall that, unlike a color-blind neuroscientist, most of us occupied this position at some point. There was presumably a period in one's lifetime when, despite never having had an orgasm, one knew the word. Yet, when our friends confessed that they had recently felt something extraordinary, few of us turned to a study of books in order to fill this intriguing gap in our knowledge. The shorter route of first-hand experience seemed, by comparison, much more fun. So, when one finally underwent the experience, did one learn something conveyed exclusively by that experience?

I surmise that each of us privately thought "So that's what an orgasm feels like!" Only subsequent philosophical schooling can make one hesitant about the genuine novelty of this experience-and only philosophical schooling could make one take seriously the suggestion that ignorance about a conscious experience can always be remedied with more book learning.

The scientific knowledge housed in a library is not useless, but when it comes to consciousness it ostensibly leaves something out. Technological improvements can give us better brain scans, finer-grained behavioural descriptions, and maybe even sharper verbal reports. But, if the present considerations are correct, there are principled reasons why such improvements will fall short of conveying what a given conscious episode feels like. Unless, that is, scientific papers on orgasms always end by saying: "Oh, and go have one."

\section{The Ordinary Knowledge Argument, More Comfortable Version}

If ordinary and scientific descriptions cannot fully convey the feel of a conscious experience, then what is being left-out? The catch-all term for this residue, originated by the American polymath and pioneer in semiotics Charles Sanders Peirce, is "qualia". This term, which is the shortened form of "qualisign", ranges over more than orgasms. So, to show how the foregoing lesson about the limits of linguistic description generalizes, I want to repeat my ordinary knowledge argument with another, less provocative, example: what is it like to taste/smell durian fruit?

This is a useful example because, unlike orgasms, many people have no clue what this qualia is. It is therefore interesting to listen to a dialogue between those who have tried durian and those who have not. Those who once ate the fruit invariably employ the same appeal to analogy discussed 
earlier. Yet, such appeals stand a chance of working only if they relate an unknown experience to a known one. If, for instance, I compare the smell of durian to the Indian cooking spice asafoetida, my comparison will not improve your epistemic lot if you have never smelled asafoetida.

Those eager to figure out what we are talking about can thus turn to the internet for guidance. The Wikipedia (2019) entry for "Durian" gives the following quote from Alfred Russell Wallace:

The five cells are silky-white within, and are filled with a mass of firm, cream-coloured pulp, containing about three seeds each. This pulp is the edible part, and its consistence and flavour are indescribable. A rich custard highly flavoured with almonds gives the best general idea of it, but there are occasional wafts of flavour that call to mind cream-cheese, onion-sauce, sherry-wine, and other incongruous dishes. [...] It is neither acidic nor sweet nor juicy; yet it wants neither of these qualities [...].

Wikipedia (2019) also cites the food and travel writer Richard Sterling, who describes the fruit's odour as "pig-shit, turpentine and onions, garnished with a gym sock" and adds that "[o]ther comparisons have been made with the [thick yellowish musky-odoured substance found in a sac near the anus of the civet], sewage, stale vomit, skunk spray and used surgical swabs."

To the outsider, it is not at all clear how this eclectic barrage of adjectives is supposed to sum. Looking for more precise language, one can consult scientific papers detailing the chemical composition of the durian fruit (e.g., Li et al. 2017). Since, for every unfamiliar term one encounters, one can search the internet to one's satisfaction, the resources currently at our disposal are the closest we can realistically get to the domain-specific omniscience stipulated in Jackson's knowledge argument. Still, the medium is limited.

To overcome those limitations, one can add behavioural observations. On YouTube, for example, there are numerous videos of people trying durian fruit for the first time. Once again the medium, while richer, is limited. Far from helping, these videos only reinforce the sense that this is truly a quality that one must experience oneself.

Given that Mary the neuroscientist suffers only from a local ignorance, my suggestion is that we can find an unknown quality that puts us in her situation -without being raised in a black-and-white environment from birth. So, if one believes that the words, numbers, and diagrams employed in scientific practice do not have the sort of limits that proponents of qualia argue they do, one can drop the speculations and actually test the situation. 
Such a test comes in three stages that map onto the segmented timeline discussed earlier. The initial period consists in not knowing the relevant word. That time has passed, since by now one already knows that there is a fruit called "durian". Whether one can occupy the second stage depends on one's personal history. If one has tasted durian before, it is too late to turn back the clock and recapture one's pre-qualitative ignorance. Hence, the people who can test my ordinary knowledge argument are those who have learned the word "durian" but have never tasted or smelled the actual fruit (for convenience, I use the verb "to eat" to capture both tasting and smelling).

For people in that position who wish to conduct the test, the protocol is quite simple. Browse the internet until you are confident that you know what it's like to eat durian fruit. This could take a while, but there are no time constraints. In fact, the longer the period of online research, the more conclusive the test becomes. Read and watch everything you can, short of tasting and smelling an actual durian. Transition from the second to the third stage happens when, mimicking Mary's emergence, one comes face to face with the genuine article. So, when confidence in your internetgleaned knowledge by description reaches its apex, go to your nearest Asian grocery store, purchase a durian, and enjoy. Then, pay attention.

As a spoiler alert, we will have a taste test at the end of my talk. Admittedly, the novelty of eating a fruit cannot match the intensity of an orgasm, but it should nevertheless give you a vivid appreciation of the core situation that drives my philosophical work on qualia. The question one must ask oneself upon actually eating the fruit is the following: is it really the case that experiencing the durian fruit first-hand added nothing to one's knowledge?

Like any serious experiment, it is important to answer this question in an unbiased way. So, ideally, tasters should train themselves beforehand in the methods outlined in Shaun Gallagher and Dan Zahavi's excellent manual on phenomenology (2008: 21-28). If one wants to trade this approach for the "heterophenomenology" outlined by Daniel Dennett (2003), then one can conduct the test with a large sample of random people and ask them whether eating the actual fruit added something to their knowledge by description. If the overwhelming answer given is "Yes", then one has to take these reports at face-value, since phenomenology and heterophenomenology exhaust the logical terrain.

Even so, to the extent that phenomenology and heterophenomenology (i.e., regular science) both express their results in linguistic signs, both face limitations. What can one say about the new experience that 
one undergoes when one finally eats durian? Since the issue pertains to the limits of language-compatible knowledge, and since the conclusion is that qualia escape the net of linguistic description, it might be appropriate to follow Wittgenstein's (1921: 89) famous seventh clause and shut up. At some point, theorizing must stop.

\section{A Few Words about Staying Silent}

Now, one might worry that ' $[\mathrm{t}]$ he idea of 'Tractatus 7.1' —an explanation of Tractatus 7-seems like a contradiction, or a violation" (Caws 2006: 11). I am not so sure. Of course, if one conducts one's inquiry as a philosopher of language, then doubling-down on language when one has reached the breaking point of language is a misguided strategy. That is why I switch from philosophy of language to philosophy of signs. Indeed, the advantage of semiotic inquiry over regular philosophy of language is that one gets all the resources afforded by linguistic signs, plus other non-verbal resources, such as indices and icons. In this way, an account of consciousness growing out of Peirce's semiotic work can provide tools to demystify the "show" portion of Wittgenstein's remarks.

Such demystification is sorely needed. For example, near the end of his Tractatus, Wittgenstein makes three rapid-fire claims: "There are, indeed, things that cannot be put into words. They make themselves manifest. They are what is mystical" (1921, section 6.522: 89; emphasis in original). This is an unfortunate cluster of claims, since one can accept that some experiences cannot be put into words and are indeed manifest-all while denying that this silence and self-evidence are in any way "mystical". Even if we suppose that the conditional "If $\mathrm{x}$ is mystical, then $\mathrm{x}$ is ineffable" is true, there is no valid inference from that premise to the conclusion "If $\mathrm{x}$ is ineffable, then $\mathrm{x}$ is mystical." It takes a biconditional to license that inference, but we have no reason whatsoever to endorse an equivalence between ineffability and mysticism.

Much the opposite, I regard the work of sub-verbal signs to be wholly consistent with the scientific method. After all, if a naturalist "goes through the trouble of taking a flat-Earther into space and asks that sceptic to look out the window, it is expected that the verdict rendered by such an experience will be decisive. If, upon viewing our spherical planet from space, our interlocutor continues to maintain that the Earth is flat, we are fully within our rational rights to dismiss that interlocutor and halt our efforts at persuasion" (Champagne 2020: 163). Epistemologists like Wilfrid Sellars (1956) have argued that such appeals cannot hold sway in rational contexts, but I would argue that, in assessing the truth of claims 
(scientific or otherwise), conscious experience is paramount (see Champagne 2016). In assessing whether qualia are present in our conscious lives, things should be no different.

That is not to say that there are no smart people who deny qualia. However, many of the usual objections to Jackson's argument about Mary cease to apply when it comes to my version involving durian. It would be bizarre, for instance, to hold that, when one experiences the fruit in question, all that one acquires is some sort of "know-how" (Nemirow 2007). Maybe one learned how to crack open the durian's spiky shell-I am willing to grant that. But, the idea that tastes and smells are skills, even if it fits well with a functionalist input-output scheme, makes little sense to me. The so-called "ability hypothesis" is only plausible where abilities are involved. Here, I detect none.

One could also resist the conclusion about a novel experiential quality by replying that one could and should have searched the internet more extensively beforehand. Fair enough. After all, my ordinary knowledge argument cannot have the force of Jackson's version, because my version concedes that a person wishing to take the bookish route will never attain omniscience. You will die before you are awarded all the PhDs needed to be a super-expert on durians (or orgasms). Surely, though, such epistemic limitations should not bother a naturalist. I do not think the novelty of a first-hand encounter will dissipate by engaging in more detailed preparatory studies. If one points out that this conclusion is not fully established because it involves a partially-informed subject, then I count that as a virtue, since we are all partially-informed subjects.

A more interesting and less explored issue in the vicinity would be to ask what would happen if the internet in my experimental design was enhanced to include tastes and smells. The attempt to simulate smells is as old as perfume, but in the 1960s special theatres tried to enhance movie-goers' experience with aroma dispensers. Although the smells could be released, they lingered on, to the point that customers became nauseated with them. A virtual reality company named All these Worlds has recently developed a scent collar that uses wireless technology to emit up to ten custom scents. These scents stop when the airflow stops. Cognitive engineers are hoping that these aromas will trigger memories and thus powerful emotions. Those trying to simulate tastes are after even bigger game. Indeed, the company named Project Nourished pitches its research and development program by asking: what if you could eat anything you want without regret? Enjoying conscious qualia without 
coming into contact with the usual physical substrate would be the Holy Grail of weight loss.

Yet, whatever design engineers eventually arrive at, that design will be answerable to one crucial constraint, namely that the felt end-result must resemble what(ever) one wants to evoke. In other words, scientists are looking for better and better icons.

\section{Unpacking the Expression “So That's What It's Like!"}

An icon is a sign that refers to its object by resembling its object. If $a$ leads to $a^{\prime}$, then $a$ gets the label of "sign-vehicle" and $a^{\prime}$ gets the label of "object", but that sense of direction can just as well be reversed, because similarity is a symmetrical relation. It is also, at minimum, a two-place relation, in this case between $a$ and $a^{\prime}$ (which become triadically related when interpreted). Since the ultimate form of resemblance would be complete replacement, the best icon would be a sign that is its object. Hence, the ultimate way for an internet user to learn the smell, taste, and texture of a durian is to order one online.

Of course, if you eat an actual durian, you get the physical substrate and thus the calories. Yet, given that the qualia and the token thing always come together, can we really distinguish the experiential quality from the thing that prompts it? Much of my work over the past decade has been devoted to unpacking the persistent sense that, as bizarre as it may seem, we can make such a distinction.

As I recount in my book Consciousness and the Philosophy of Signs (Champagne 2018), Peirce's term "qualia" got picked up by analytic philosophers, but the theoretical framework behind it remained mostly ignored. Going back to Peirce's original formulation can thus shed light on the ideas and faculties that risk making the qualitative dimension of consciousness look foreign.

Peirce writes that "[a] Qualisign is a quality which is a sign. It cannot actually act as a sign until it is embodied; but the embodiment has nothing to do with its character as a sign" (1903: EP2.291). For example, if I want to convey to you the vibrant hue of Batwoman's hair by using an exemplar instead of a word, it doesn't matter whether I use a red wig or Santa's suit, since the vehicle that will let interpretation reach the sign's intended object is the colour, not the thing that bears it. This applies to all qualities. As a matter of empirical fact, we humans can indeed distinguish between a putrid smelling thing and a putrid smell. One must be careful, however, to construe that distinction only in a weak sense, otherwise one will lapse into a reification of the quality at hand. Taking stock in an unbiased way 
of the before-and-after transition that happens when one eats a durian should therefore remain instructive.

As Jackson put it in his classic paper, "when [Mary] is let out of the black-and-white room [...] she will not say 'ho, hum."” (1986: 291). The same goes for people trying durian for the first time. As the YouTube videos attest, first time eaters are everything but indifferent to their novel conscious experience. Like Mary, none of them say "Meh." Similarly, I doubt participants to my ordinary knowledge argument will say "I could have worked all this out before by making some more purely logical inferences" (Jackson 1986: 292). Hence, one's first orgasm or durian is not just novel, it is surprising.

We experience surprise only when we are exposed to something genuinely external to our habitual expectations. As Peirce was fond of saying, we cannot startle ourselves merely by saying "Boo!" (1903: EP2.195). The sense of surprise that accompanies a first contact with a new quality is thus something that any adequate theory of the mind must square with (or at least do justice to).

In my estimate, the expression "So that's what it's like to experience ..." has been inadequately analyzed in the mainstream philosophical literature. Today, I cannot do justice to the complex tissue of issues that this expression raises, but one way to summarize my discontent with its current treatment would be to say that, while analytic philosophers of mind tackle their subject with twofold distinctions inherited mainly from Bertrand Russell, I think we should be tackling the subject with threefold distinctions inherited from Peirce.

So, while it is customary to distinguish between types and tokens, I think we need to distinguish between types, tokens, and tones. Moreover, while it is customary in the current literature to distinguish between knowledge by description and knowledge by acquaintance (Knowles and Raleigh 2020), I think acquaintance is a genus with two species, such that we need to distinguish between knowledge by indexical acquaintance and knowledge by iconic acquaintance (although I prefer to avoid the latter expression and use simply "iconicity").

\section{A Methodology for Unpacking the Expression "So That's What It's Like!"}

My argument involving orgasms and durians hopefully prompts a realization that there is a genuine problem here. Whether and to what extent it constitutes a "hard" problem is another question. A lot of people think it is (Chalmers 1995). However, I have inherited from Wittgenstein (c.1951) 
and my doctoral grandfather (Doktorgrossvater) John McDowell (1994) a suspicion that some problems that occupy professional philosophers are, to put it bluntly, made-up problems, at least in part. When this is the case, what is required is not more ardent theorizing-much less extra funding - but rather a kind of "therapeutic" philosophizing that aims to disabuse us of unhelpful ideas and replace them with a different vantage.

To achieve such a fresh vantage, it is often useful to reconnect with defunct ways of seeing things. So, while I am not (and have no wish to become) a historian, my attempt to retrace the origins of mainstream assumptions leads me to engage with the past. This is an unusual approach, since "[p]hilosophers of mind seldom discuss or investigate, more than cursorily, the history of the interrelated concepts of mind, consciousness, experience, and the physical world that they rely upon in their theorizing" (Livingston 2004: 1). Frank Jackson, for instance, recently told me that, prior to reading my book, he had no idea that his argument was formulated centuries earlier by John Locke (in his Essay, book 2, chapter 1, paragraph 7), the same philosopher who coined the term "semiotics". As for Jackson's knowledge of Peirce, an Australian colleague of mine once told me that, when she asked Jackson years ago to supervise her budding dissertation on Peirce, Jackson replied that he knew two things about the American thinker: "First, he is mentioned in [David M.] Armstrong's book on universals. Second, wasn't he a drunk?” Jackson's 2010 book Language, Names, and Information, shows that his engagement with Peirce never moved past that stage. So, despite titling his classic paper "Epiphenomenal Qualia", Jackson never explored the fact that the term qualia was pulled from a sophisticated semiotic account.

As someone privy to the vast but vastly underexplored writings of Peirce, I try to rectify historical oversights like these. I also tend to give medieval philosophy more credence than the norm; a reflex I inherited from the late John Deely (2001).

My methodological prescription, in a nutshell, is this. First, switch from philosophy of language to the wider disciplinary ambit of philosophy of signs, since the latter encompasses the former while offering still more semiotic resources. Second, find out where your concepts came from, historically, so as to be more critical about the merits and demerits of those concepts. Third, get as clear as you can about key Peircean notions, notably prescissive abstraction, the type/token/tone distinction, and the subdivision between indexical and iconic acquaintance. Then, once all this has been done, revisit the usual pro-qualia arguments like Jackson's 
knowledge argument. My sense is that, if one follows those steps in earnest, many things will fall into place (or at least look less mysterious).

To be clear, my strategy does not consist in asking whether qualia exist. Far from being neutral, mainstream debates about consciousness are typically permeated by a fear that, if we acknowledge the presence of experiential qualities in our mental lives, we will somehow cede terrain to a bogeyman called "dualism". At the risk of holding a minority view, I have no time for this traditional dispute, primarily because I fail to see what is at stake in it. When did philosophy of mind become a department of metaphysics? I certainly didn't get that memo. Metaphysics is a legitimate and highly interesting field of inquiry (see Champagne 2015), but it clouds one's thinking in philosophy of mind to think about it. So, while Jackson's preferred conclusion was that "physicalism is incomplete" (1982: 130), I prefer to conclude that the representational range of physicalism's preferred signs is incomplete, insofar as verbal and mathematical symbols can carry a great deal of information but not everything into Mary's confines.

My goal is thus to get clear on the various stated and unstated semiotic assumptions involved in discussions of consciousness. My hypothesis is that unnoticed conceptual omissions are often what render consciousness mysterious. If someone like Dennett (1988) can uncharitably explain away the intuitions that lead people to believe in qualia, surely I can charitably explain those intuitions.

I am impressed by the idea that the only sign inside Mary's room capable of representing the red things outside her room would be a sign that is red. So, instead of adding an extra stuff to the standard ontology of matter, I recommend that we add an extra sign — the icon—to the standard repertoire of indices and symbols. In this regard, I side with philosophers of mind (known as "phenomenal concept strategists") who argue that worries about qualitative mental states stem from the special concepts used to describe those states. I am not sure whether such an approach is modest or ambitious. In a way, it could be seen as modest, since it does not pretend to yield an account of how immaterial minds arise from purely material substrates. I instead want to clarify a set of distinctively human abilities that, when misunderstood or ignored, have the power to alienate us from a familiar portion of the human condition.

Yet, this search for a dissolution instead of a solution could be seen as ambitious, because it requires important modifications of what are, for many analytic philosophers, settled distinctions. You just have to be a substance dualist, property dualist, or materialist monist, yet I dismiss most of those "isms" as unproductive, to the point where I don't even 
mention them. In so doing, I willingly jettison much of my schooling. Or, to be more precise, I use my schooling to determine which assumptions ought to be jettisoned. That might be revolutionary (in Thomas Kuhn's sense) or just plain effrontery. Still, for better or worse, rethinking the qualitative aspect of the mind in Peircean semiotic terms is the approach I have essayed in Consciousness and the Philosophy of Signs.

\section{Outline of a Possible Semiotic Account}

Concretely, my foray results in the following account:

- Mastery of language is necessary.

- Mastery of language is not sufficient.

- Indexical exposure to an actual token is necessary.

- Indexical exposure to an actual token is not sufficient.

- The token must have the right quality.

- Provided that the token has the right quality, it can be any token.

- The presence of similar tokens is inessential.

- The presence of this token is in some way inessential.

Let me briefly comment on each claim.

Mastery of language is necessary. Many creatures are conscious, but creatures capable of worrying about their consciousness are creatures capable of using (lay or specialized) language about consciousness. I contend that we must stop talking at some point, but I want to be equally adamant that what happens during such a period of silence is informative only because we talked about it beforehand. In fact, I would suggest that, the more we talk about a quality, the more momentous our iconic-acquaintance becomes. Experiential qualities do not depend on conventions to be what they are, but we burrow into those relation-less qualia from a network of conventional relations and accepted practices that never vanishes.

Mastery of language is not sufficient. As the knowledge argument establishes, we cannot accomplish everything by talking more.

Indexical exposure to an actual token is necessary. As the knowledge argument also establishes, you need to actually eat a durian fruit in order to appreciate what it's like. Nothing I say in my book changes the need for such a direct contact.

Indexical exposure to an actual token is not sufficient. Even if we grant that Mary will have to exit, it remains an open question how to refer to the 
qualitative experience that she will have. The experience that one is having is happening here now, so it is reasonable to convey it with a demonstrative. However, the expression "This one here now" does not convey what is here now. The indices jointly succeed in isolating a region of experience, but if an account does not go beyond this indexicality, it risks occluding the additional iconic work that renders such an ostensive appeal informative.

The token must have the right quality. Since the qualitative content matters, if I bring you face to face with, say, a jackfruit, you won't get acquainted with durian. Similarly, if what Mary sees upon leaving is blue, she learns blue, not red.

Provided that the token has the right quality, it can be any token. At the point of purchase, I had to make a choice between several almost-identical durians. I picked this one, but the specimen immediately next to it would have worked just fine to convey the quality in question. Similarly, Mary can learn red from a red rose or a red apple-or a red whatever. That is why Peirce writes that "[a] Qualisign [...] cannot actually act as a sign until it is embodied; but the embodiment has nothing to do with its character as a sign" (1903: EP2.291). Moreover, the important thing is being of the right quality, not belonging to the same natural kind. Even within the natural kind "monthong durian" that I bought, distinct tokens will present slight variations in their flavours, so a ripe taste will obviously differ from an unripe one. But, at the proper level of analysis, an unripe taste does not differ from another unripe one. Hence, I could imagine a durian-lover looking to recreate the experience, not just of any monthong durian, but of a memorable individual that they enjoyed on a particular occasion. Properties that are "accidental" from the point of view of classification thus have their own "essence" from the point of view of philosophy of mind.

The final two theses bring us squarely into contrary-to-fact territory:

The presence of similar tokens is inessential. The individual durian specimen present before us is related to other individual durians currently located, say, at the Asian market. As members of the same species, they share a common lineage, so when one finds out what it's like to eat this particular durian in Toronto, one finds out what all durian are like, including those in Malaysia. This looks like action at a distance. Yet, suppose that those other durians in Toronto and Malaysia did not exist. This lack of existence would extinguish the indexical bond connecting this thing to other things. However, such an absence would do nothing to change the iconic power of the token stimulating one's sense organs. Even as the last durian on Earth, a single individual remains similar to anything that 
would be like it. So, while similarity is a two-place relation, the quality that grounds similarity can be housed wholly in a given relatum.

The presence of this token is in some way inessential. While the need for an actual exposure suggests that one can capture the qualia at hand with a purely causal account, icons have distinctive modal properties that causality fails to capture. As we have just seen, icons don't require the objects they signify to actually exist. What's more, the referential work enabled by qualities does not even pivot on their actual physical instantiation, as necessary as that instantiation might be. To see why, go further and suppose that this actual durian before us did not exist. It seems sensible to say that, were it to exist, it would be similar to any other durians, were they to exist too. The philosophical moral is that qualities do not depend on their actual material instantiation in order to fix their iconic scope. It suffices that a quality be such-and-such (as opposed to being thus-and-so) to establish that the quality would be like any such-and-such. That is why you can't destroy the colour red (or the inherent referential potential of that colour) simply by burning a red rose. This, on my diagnosis, is the strange-but-true feature that generates confusion over whether qualia demonstrate or fail to demonstrate "intentionality" or aboutness (see Lalor 1999). In iconicity, both sides of this perennial debate are right.

I struggled for years to accept some of the claims that I have listed, which form a minefield of potential confusion. To be clear, the suppositions of absence at play in the account just outlined go against the hard facts, since there is a durian on some market shelf somewhere, just as there is (and indeed must be) a durian before whoever eats it. But, whatever insight into the distinctive taste and smell of durian is afforded by a particular token does not hinge on the existence of other tokens. It does not even hinge on the existence of this token, since it could just as well be swapped for another. What is involved when we pinpoint the qualities at the heart of conscious experience is thus an artificial separation that Peirce called prescissive abstraction.

Peirce took this from Duns Scotus, who defined the "formal distinction" in contrast with the "real distinction". A real distinction allows one to keep a thing present while factually making another thing absent, whereas a formal distinction can only suppose that the other thing is absent. It is this ability to prescind, I argue, that underpins a common locution like "I don't mean this durian flesh, I mean its flavour." That fragment of language makes it seem as if the flavour can exist apart from the flesh. As a brute fact of our universe, it cannot. We are nevertheless endowed with the ability to consider that flavour apart from the flesh. 
Precission is thus crucial to understanding the qualitative dimension of consciousness. A mental state usually brings into play a stimulus and a response. John Dewey was right in his early psychological papers to warn that, since any organism is coupled to its environment in an embodied way, this entire "reflex arc" must be psychology's minimal unit of analysis (Dewey 1896). The same warning can be found in the seminal biological work of Jakob von Uexküll (1926: 155), who focused on the perceptual and motor "function-circle" as a whole. Contemporary analytic philosophy of mind, where functionalism dominates, has mostly followed suit. However, a philosophical account is not a psychological or biological account, so with Peirce I argue that there is a way to meaningfully allude to the qualitative character of a stimulus, apart from whatever response it stimulates or other detectable effects it has.

We humans have available to us a perspective that makes sense of qualia, but not only must this perspective go against natural science, it must go against the deliverances of phenomenology too. Qualia are supposed to be what they are irrespective of the various causal or inferential roles they enter into. But, to quote Dewey, we are no more conscious of "this or that color or sound by itself" than we are "of motion as motion" (1896: 369). Hence, whatever lets us know qualia, it isn't introspection.

\section{Conclusion}

To conclude, I do not think we fully understand this ability to focus on some aspect to the exclusion of another. Yet, I do not think we need to fully understand this ability in order to acknowledge that we possess it. I am not sure how much light my written work has managed to cast on prescission, iconicity, and their roles in conveying qualities, but studying these notions strikes me as more promising than figuring out how ghostly mind-stuff magically arises from inert matter.

My work instead seeks to understand what, from a strict semiotic standpoint, happens when people see a new colour, experience their first orgasm, or consume an exotic fruit and exclaim "Now I know what you mean." Subjects don't even have to verbally express this iconic acquaintance. Far from being mystical or inimical to the conduct of natural science, I want to place such silent nodding at the core of all inter-subjective understanding. I believe this can done if we carry some powerful but neglected ideas from Peirce over to mainstream debates about consciousness.

As I said at the outset, any loose ends I may have generated today are likely tied in my book. What you will find there are conceptual tools that let one look at mental goings-on in a renewed and, I would argue, more 
fruitful way. Such a project of applying philosophy of signs to consciousness cannot be completed by a single person, so hopefully the remarks I made today will be built upon by co-workers.

In any event, in keeping with my insistence that language has its limits, I now end my talk and invite you to become iconically acquainted with a strange and wondrous fruit. ${ }^{2}$

\section{References}

CAWS, Peter.

2006. "Tractatus 7.1: Translation and Silence", Philosophy Now 58, 10-12.

CHALMERS, David J.

1995. "Facing Up to the Problem of Consciousness", Journal of Consciousness Studies 2.3, 200-219.

CHAMPAGNE, Marc.

2015. "A Less Simplistic Metaphysics: Peirce's Layered Theory of Meaning as a Layered Theory of Being", Sign Systems Studies 43.4, 523-552. https://doi.org/10.12697/SSS.2015.43.4.10

2016. “Tracking Inferences is not Enough: The Given as Tie-Breaker", Logos and Episteme 7.2, 129-135. https://doi.org/10.5840/logos-episteme20167214

2018. Consciousness and the Philosophy of Signs (Cham: Springer).

2020. Myth, Meaning, and Antifragile Individualism (Exeter: Imprint Academic).

DEELY, John N.

2001. Four Ages of Understanding: The First Postmodern Survey of Philosophy from Ancient Times to the Turn of the Twenty-first Century (Toronto: University of Toronto Press).

DENNETT, Daniel C.

1988. "Quining Qualia", in Consciousness in Modern Science, ed. Anthony J. Marcel and Edoardo Bisiach (Oxford: Oxford University Press), 42-77.

1991. Consciousness Explained (New York: Little, Brown and Company).

2003. "Who's On First? Heterophenomenology Explained", Journal of Consciousness Studies 10.9-10, 19-30.

DEWEY, John.

1896. "The Reflex Arc Concept in Psychology", Psychological Review 3.4, 357-370. https://doi.org/10.1037/h0070405

${ }^{2}$ Editor's Note: At this point, a fresh durian was carved and served at the front of the auditorium to those in attendance, who eventually ate the whole fruit. 
GALLAGHER, Shaun, and Dan ZAHAVI.

2008. The Phenomenological Mind: An Introduction to Philosophy of Mind and Cognitive Science (London: Routledge).

HARNAD, Stevan.

1990. “The Symbol Grounding Problem”, Physica D: Nonlinear Phenomena 42.1-3, 335-346. https://doi.org/10.1016/0167-2789(90)90087-6

JACKSON, Frank.

1982. "Epiphenomenal Qualia”, The Philosophical Quarterly 32.127, 127136. https://doi.org/10.2307/2960077

1986. “What Mary Didn’t Know”, Journal of Philosophy 83.5, 291-295. https://doi.org/10.2307/2026143

2010. Language, Names, and Information (West Sussex: Wiley-Blackwell).

KNOWLES, Jonathan, and Thomas RALEIGH, Editors.

2020. Acquaintance: New Essays (Oxford: Oxford University Press).

LALOR, Brendan J.

1999. “Intentionality and Qualia”, Synthese 121.3, 249-290.

LI Jia-Xiao, Peter SCHIEBERLE, and Martin STEINHAUS.

2017. "Insights into the Key Compounds of Durian (Durio zibethinus L. 'Monthong') Pulp Odor by Odorant Quantitation and Aroma Simulation Experiments", Journal of Agricultural and Food Chemistry 65.3, 639-647. https://doi.org/10.1021/acs.jafc.6b05299

LIVINGSTON, Paul M.

2004. Philosophical History and the Problem of Consciousness (Cambridge: Cambridge University Press).

MCDOWELL, John $\mathrm{H}$.

1994. Mind and World (Cambridge, MA: Harvard University Press).

NEMIROW, Laurence.

2007. "So This is What it's Like: A Defense of the Ability Hypothesis", in Phenomenal Concepts and Phenomenal Knowledge: New Essays on Consciousness and Physicalism, ed. Torin Alter and Sven Walter, 32-51 (Oxford: Oxford University Press).

PEIRCE, Charles Sanders.

i.1893-1913. The Essential Peirce: Selected Philosophical Writings, Vol. 2, ed. Peirce Edition Project (Bloomington: University of Indiana Press, 1998). Cited as EP2.

RUSSELL, Bertrand.

1910-1911. "Knowledge by Acquaintance and Knowledge by Description", Proceedings of the Aristotelian Society 11, 108-128.

https://doi.org/10.1093/aristotelian/11.1.108 
SEARLE, John R.

1980. "Minds, Brains, and Programs", Behavioral and Brain Sciences 3.3, 417-424. https://doi.org/10.1017/S0140525X00005756

SELLARS, Wilfrid.

i.1956. Empiricism and the Philosophy of Mind, with an introduction by Richard Rorty and a study guide by Robert Brandom (Cambridge, MA: Harvard University Press, 1997).

UEXKÜLL, Jakob von.

1926. Theoretical Biology (New York: Harcourt, Brace and Company).

WIKIPEDIA.

2019. “Durian”, Wikipedia. Available at en.wikipedia.org/wiki/Durian. Accessed 17 December 2019.

WITTGENSTEIN, Ludwig.

1921. Tractatus Logico-Philosophicus, trans. David F. Pears and Brian F. McGuinness (London: Routledge, 1974).

c.1951. Philosophical Investigations, trans. G. E. M. Anscombe (Oxford: Blackwell, 2001). 